\title{
La huelga de Alpargatas en 1979: las nociones de lo justo en dictadura
}

\author{
Gabriela Mitidieri \\ Universidad Nacional de Buenos Aires
}

\section{Resumen}

Este artículo busca reconstruir la huelga de la fábrica textil argentina Alpargatas Barracas, conflicto que tuvo lugar a fines del mes de marzo y principios del mes de abril de 1979. Para tal fin, me propongo caracterizar de manera pormenorizada el espacio laboral y las relaciones sociales que se entramaron al interior del mismo. Además serán analizadas, a partir de las pistas brindadas por el testimonio de diferentes obreros y obreras, algunas de las estrategias puestas en marcha para negociar condiciones más justas de trabajo, en el marco de la última dictadura militar.

\section{Palabras clave}

mundos del trabajo, demandas por derechos, huelga, Alpargatas, dictadura

\begin{abstract}
The aim of this article is to reconstruct the worker's strike that took place in the Argentinean textile factory Alpargatas Barracas, on the last days of March and the first days of April, 1979. To do so, I seek to describe with detail Alpargatas work place and the social relations intertwined there. Also, from a series of workers testimonies, I will analyze the strategies set in motion by them in order to negotiate fairest work conditions within the frame of the last Argentinean military dictatorship.
\end{abstract}

\section{Keywords}

worlds of labour, claims for rights, strike, Alpargatas, dictatorship 


\section{La huelga de Alpargatas en 1979}

\section{Introducción}

Entonces en el año '79 empezaron ellos a pedir un aumento, una cosa y la otra y había chicas que los maridos trabajaban ahí y empezaron a... ponían carteles, me acuerdo, en las ventanas que estaban parando. Hubo quien paró y quien no, ahí donde estábamos nosotras. $\mathrm{Y}$ ahí, mis compañeras me preguntan: ‘ $Y$ Neli? ¿Paramos? ¿No paramos?' 'Y, mirá, yo me acuerdo que mi mamá, en el año '59, mi mamá, ¡45 días! todos los textiles habían parado, no Alpargatas. Todos los textiles. $Y$ entraron como... ipeor todavía! porque después había que bancársela.' (...) En el sector éramos dos. ¡De 400, 500 personas habrán entrado 15! Y ahí hicieron la gran limpieza que ellos querían hacer. Esa fue la historia. (...) De las delegadas, ninguna entró.

Neli fue una de las casi 4000 personas que, en tanto que trabajadores, vivieron la única huelga documentada de la fábrica textil Alpargatas Barracas durante el período signado por la última dictadura militar (1976-1983). Su testimonio es una puerta de entrada a la experiencia de clase de una trabajadora en este contexto: la de una obrera cuya participación en el conflicto se articuló a su vez con aprendizajes vivenciados en el seno de una familia trabajadora. Así mismo, las palabras de Neli arrojan luz acerca de qué diferentes estrategias en pos de aquello que se consideraba que correspondía por derecho fueron puestas en marcha por distintos grupos de trabajadores de Alpargatas y cuál fue el desenlace de la huelga para ellos. De este modo, dicha huelga puede funcionar como prisma que nos permite aproximarnos a esas perspectivas.

El presente artículo se propone reconstruir y analizar una huelga que tuvo lugar en la fábrica textil Alpargatas Barracas, en los últimos días del mes de marzo y primeros del mes de abril de 1979. El objetivo es indagar en la huelga en tanto arena de conflicto en la que pueden rastrearse distintos sentidos acerca de lo que los trabajadores consideraron justo o que les correspondía por derecho.

Esta huelga tiene la particularidad de haberse llevado a cabo en el contexto adverso de la última dictadura militar, adversidad que se expresó en la no vigencia de derechos laborales y gremiales y en la persecución del activismo políticosindical, con la connivencia en muchas oportunidades de los propios directivos de empresa ${ }^{1}$. Al ser la medida considerada ilegal, situación puesta de manifiesto por la propia patronal a lo largo del conflicto, existieron trabajadores que decidieron no tomar parte activa en la realización del paro. En tal sentido, esta pesquisa se propone, en segundo lugar, revisar qué otras estrategias de negociación y disputa por aquello que se consideraba que correspondía por derecho fueron puestas en práctica. Se espera así poder aportar a la historiografía que estudia las

\footnotetext{
${ }^{1}$ Ver V. Basualdo, Complicidad patronal-militar en la última dictadura argentina: Los casos de Acindar, Astarsa, Dálmine Siderca, Ford, Ledesma y Mercedes Benz, Revista Engranajes (Federación de Trabajadores de la Industria y Afines), №5, 2006.
} 


\section{Gabriela Mitidieri}

manifestaciones de oposición y resistencia a la dictadura en Argentina, dando cuenta de la heterogeneidad interna de la propia clase y sus experiencias ${ }^{2}$.

En los últimos años, existen investigaciones que han abordado a los trabajadores y a las trabajadoras de la fábrica Alpargatas como objeto de análisis. Mariela Ceva ${ }^{3}$ centró su estudio en los orígenes de la empresa, las modalidades de ingreso de nuevos operarios, asociadas a redes familiares y comunales y las características de la industria textil y del mercado laboral de dicha rama, hasta el golpe de estado de 1955. Para su análisis se basó en la conformación de un contrapunto entre Alpargatas y la Algodonera Flandria,(ubicada en?) una fábrica de menores dimensiones. De acuerdo a su investigación, Alpargatas promovía la contratación de nuevos trabajadores a través de recomendaciones de su personal. Esto era ilustrativo de una modalidad presente en este y otros establecimientos textiles que propendía a la creación de un ambiente familiar de trabajo y era parte de un conjunto de medidas caracterizadas por ella como paternalistas. La prolongación de lazos de parentesco al interior de la fábrica traía aparejada una serie de obligaciones recíprocas entre distintos rangos jerárquicos que, según Ceva, contribuyeron a la consolidación de un ideal de armonía fabril. Si bien la autora elige poner el énfasis en el modo en que dicho ideal permeó las experiencias de los trabajadores, también son abordados en su investigación algunos aspectos de la conflictividad laboral al interior de la empresa, por ejemplo durante el primer peronismo. Momentos de conflictividad en Alpargatas son abordados posteriormente y en profundidad tanto por Marcos Schiavi ${ }^{4}$ como por Victoria Basualdo $^{5}$. El primero realiza una indagación en torno a la fábrica durante la primera presidencia peronista, analizando en particular la lucha por el reconocimiento de comisiones internas y la huelga que tuvo lugar en diciembre de 1946. En su tesis doctoral, Victoria Basualdo afronta el período 1943-1983, a través de un estudio comparativo entre la fábrica textil Alpargatas (Barracas y Florencio Varela, Buenos Aires) y el caso del complejo metalúrgico Acindar (Villa Constitución, Santa Fé). La huelga de Alpargatas Barracas de 1979 es analizada por

\footnotetext{
${ }^{2}$ Ver por ejemplo, V.Basualdo, La participación de trabajadores y sindicalistas en la campaña internacional contra la última dictadura militar argentina, en Revista Sociedad No. 25, Facultad de Ciencias Sociales de la Universidad de Buenos Aires, 2006 y Labor and structural change: Shop-floor organization and militancy in Argentine industrial factories (1943-1983), Tesis de Doctorado, Columbia University, 2010; D.Dicósimo, Dirigentes Sindicales, racionalización y conflictos durante la última dictadura militar en Revista Entrepasados, Año XV, № 29, 2006; F.Lorenz, Los zapatos de Carlito. Una historia de los trabajadores navales de Tigre en la década del 70, Ed. Norma, 2007; A.Schneider, Ladran Sancho... Dictadura y clase obrera en la zona norte del Gran Buenos Aires, en H. Camarero, P. Pozzi y A. Schneider, De la Revolución Libertadora al Menemismo. Historia Social y Política Argentina, Ed. Imago Mundi, 2000, entre otros.

${ }^{3}$ M.Ceva, Empresas, trabajo e inmigración en la Argentina. Los casos de la Fábrica Argentina de Alpargatas y la Algodonera Flandria (1887-1955). Ed. Biblos, 2010.

${ }^{4}$ M.Schiavi, Organización y conflictividad textil:La Fábrica Argentina de Alpargatas a comienzos del

primer gobierno peronista. Revista Mundos do Trabalho, vol. 4, n. 8, 2012, p. 252-272.

${ }^{5}$ V.Basualdo, Labor and structural change: Shop-floor organization and militancy in Argentine industrial factories (1943-1983), Tesis de Doctorado, Columbia University, 2010
} 


\section{La huelga de Alpargatas en 1979}

esta autora en dicha investigación y existen menciones previas al episodio en los tempranos trabajos de Pablo Pozzi ${ }^{6}$ y Álvaro Abós ${ }^{7}$. En las pesquisas de ambos, el caso no es explorado de manera pormenorizada, sino que la huelga se inserta en el marco más amplio de los estudios sobre conflictividad gremial en la última dictadura militar.

Tal como repasa Basualdo, la dictadura implicó un duro revés para la clase trabajadora, y para los obreros textiles éste golpe se materializó de diversos modos: pérdida de derechos sindicales/laborales, persecución de militantes y líderes gremiales, tensiones al interior del propio sindicato intervenido, intensificación del control al interior de las fábricas, incremento del costo de vida. También en términos de políticas macroeconómicas, el cese de impuestos aduaneros para la importación de productos textiles, la financierización de la economía y la conformación de grupos económicos como el conglomerado Roberts -dentro del cual quedó comprendida Alpargatas S.A.-, son todos elementos que impactaron en el cotidiano de los trabajadores y trabajadoras de Alpargatas hacia 1979.

Este artículo se nutre de esta historiografía que en los últimos años ha fortalecido las interpretaciones sobre las luchas obreras en los años 1970 y en los tempranos 1980. Pero también se pregunta sobre qué implicaría para los y las trabajadoras de la planta Alpargatas lo justo en aquel marco de la dictadura militar. Para indagar en torno a esta cuestión, serán planteadas diferentes dimensiones. En un primer apartado, se realizará una caracterización del espacio fabril en los momentos previos a la huelga de 1979. Se analizan testimonios de trabajadores de la fábrica, delegados gremiales, y también publicaciones de la empresa y de la Federación Industrial Textil Argentina. Entrecruzar estas fuentes permite dimensionar el nivel de actividad de la planta en aquel periodo. También hace posible revisar el modo en el que el mismo fue percibido por los trabajadores. En esa sección, se analizará la historia de Neli, una operaria de Alpargatas que inició su trabajo en la empresa a comienzos de la década del '70 y se mantuvo en su puesto luego de finalizada la huelga de 1979.

En un segundo apartado, se examinará la huelga, las demandas de los trabajadores que la dinamizaron, las respuestas de la empresa y el marco general en el que se desarrolló. Las fuentes a analizar en este caso, estarán compuestas por la cobertura periodística aparecida en la prensa en los días previos, posteriores y a lo largo del conflicto. También se estudiarán los comunicados emitidos por la empresa durante la huelga y se indagará nuevamente en las palabras de Neli, y también de Alberto, mecánico de la fábrica, para acceder a una perspectiva históricamente situada del conflicto.

En un tercer momento, se abordará la organización gremial al interior de la fábrica, como modo de enmarcar la medida huelguística dentro de la tradición de política sindical de Alpargatas. Además, con la intención de complejizar la

\footnotetext{
${ }^{6}$ P.Pozzi, La oposición obrera a la dictadura. Ed. Imago Mundi, 2008 (Primera Edición: 1988)

${ }^{7}$ A.Abós, Las organizaciones sindicales y el poder militar. Ed.CEAL, 1984.
} 


\section{Gabriela Mitidieri}

perspectiva sobre esta dimensión, se revisará de qué manera el género operó como un organizador de la producción y también estableciendo jerarquías en la propia dinámica gremial intra-fabril. El apoyo heurístico será nuevamente el análisis de testimonios orales y también una revisión de la investigación de Victoria Basualdo sobre la esfera gremial en esta fábrica.

Por último, serán exploradas las nociones de lo justo que pueden ser aprehendidas en las voces de aquellos delegados y delegadas que desempeñaban su función en las vísperas y durante la huelga. De esta manera, este artículo busca reconocer cuáles fueron algunas de las consideraciones sobre derechos adquiridos que permearon las prácticas de delegados y trabajadores. Estas prácticas impugnaron de diferentes maneras el conjunto de medidas dictatoriales restrictivas de la libertad gremial entre las cuales se contaba, por ejemplo, la de derogar o modificar 125 de los 300 artículos de la Ley de Contrato de Trabajo, sancionada en 19748 .

\section{Una trabajadora ingresa a la fábrica}

Alpargatas fue una de las fábricas textiles más grandes de la Argentina. Fundada en 1885, alcanzó a emplear alrededor de diez mil trabajadores en los momentos de mayor productividad para la rama, como aquel enmarcado por el primer peronismo ${ }^{9}$. En ese sentido, cabe destacar que el estímulo brindado a la industria textil en el período de sustitución de importaciones implicó el ingreso masivo de mano de obra, mayoritariamente femenina, a las secciones productivas de las fábricas que la empresa poseía en el barrio porteño de Barracas. Esta presencia fue una constante a lo largo de la historia de la empresa y un rasgo que definió muchas de las prácticas laborales y gremiales que tuvieron lugar en su interior ${ }^{10}$.

Hacia fines de la década del '70 la Fábrica 1, aquella de mayor antigüedad, dedicaba parte de sus instalaciones a la producción de calzado: elaboración de yute, el zapato de hombre "Paso Doble" (un zapato de vestir, abotinado), diferentes tipos de cordones de zapatillas, y por supuesto, las históricas alpargatas. Una parte de la gerencia, así como los espacios destinados a las secciones administrativas y contables, convivía con las secciones productivas en aquella fábrica, con una entrada propia por la calle Olavarría. Al otro lado de la Avenida, se encontraba la entrada de la Fábrica 2. Allí estaba localizada la tintorería, las hilanderías y las

\footnotetext{
${ }^{8}$ A.Abós, op.cit. p17.

${ }^{9}$ En su estudio, Schiavi afirma que durante la década peronista Alpargatas fue "Sin duda, la mayor de las textiles algodoneras. Ocupaba alrededor de diez mil obreros, cerca del $10 \%$ del total de la actividad. Era dominante en la industria y clave en el gremio: lo que ocurría en Alpargatas impactaba en toda la subrama algodón. Esta gigantesca fábrica estaba ubicada en el barrio de Barracas, en el corazón industrial de la ciudad de Buenos Aires, rodeada de frigoríficos y empresas metalúrgicas." Schiavi op.cit. p13. Para un análisis sobre la rama textil en el período, ver C. Belini, La industria peronista: 1946-1955, políticas públicas y cambio estructural. Edhasa, 2009.

${ }^{10}$ Ver M.Ceva, Op.cit. P.30-32, 86-89.
} 


\section{La huelga de Alpargatas en 1979}

tejedurías de tela de jean. Una cuadra más allá, la Fábrica 3 concentraba las secciones de confección de tejido de limpieza (trapos de piso, franelas y trapos rejilla), también la producción de ropa de cama de primera marca ("Palette") y de segunda ("Horizon"). En el cuarto piso de esa fábrica se organizaba la producción de toda la indumentaria. Desde la década del '50, Alpargatas contaba además con una planta localizada en Florencio Varela que, hasta la actualidad, se dedica a la elaboración de zapatillas y otros tipos de calzado11. En la planta de Barracas se alternaban tres turnos de lunes a sábado para las secciones productivas: de 6 de la mañana a 14 hs, de 14 hs a 22 hs y de 22 hs a 6 am. Estos turnos solían rotar: una trabajadora que hiciera el turno mañana una semana, debería tomar el de la tarde la siguiente y así sucesivamente. Esto afectaba de igual modo a los operarios varones, pero ellos también debían alternar esta rotación con el turno nocturno, vedado para el personal femenino.

Neli12 ingresó como operaria de la fábrica Alpargatas en el año 1971. El trabajo textil estuvo presente en su vida desde muy pequeña ya que su madre había sido obrera de la fábrica Masllorens durante toda su infancia. Esta presencia continuó como un legado cuando a sus 18 años ingresó ella misma a trabajar en aquel establecimiento de Crucecita, Avellaneda, muy cerca de la casa que compartía con su familia. El fallecimiento de su padre y el anunciado cierre de la Masllorens $^{13}$ a comienzos de la década de 1970 llevaron a Neli a pensar en un puesto de trabajo mejor remunerado. Alpargatas era, en ese entonces, una de las principales fábricas textiles del país, junto con Grafa y Sudamtex ${ }^{14}$, y empleaba una

${ }^{11}$ La caracterización de las fábricas fue realizada por Hortensia, ex trabajadora y delegada gremial de Alpargatas en una entrevista realizada el 28 febrero de 2013, en la sede de la Asociación Obrera Textil, Ciudad Autónoma de Buenos Aires. Concuerda con la descripción de Basualdo en su tesis doctoral, con la descripción de Ceva hasta 1955 y con la organización espacial registrada en los anuarios de la fábrica durante la década del ' 40 , a la que se le suma la tejeduría de tela de jean durante la década del '70. De igual modo, se registran las secciones mencionadas en la publicación de la Asociación Obrera Textil, el gremio de la rama, hasta el año '69. El archivo del sindicato no cuenta con los números editados durante la década del '70 y la publicación no fue editada mientras duró la intervención del sindicato, en dictadura. De manera similar es mencionada en el libro Fábrica Argentina de Alpargatas S.A.: ¿Argentina o de los monopolios? Partido Comunista del Barrio de La Boca, Ed.Anteo 1974. Nos detalla que a comienzos de los años '70 la empresa contaba con una hilandería de algodón moderna; sección tejeduría con telares automáticos y semiautomáticos; tintorería industrial, con maquinaria para terminación, descrude, sanforizado y estampado a schablón; hilanderías de yute con máquinas modernas, hilanderías de fibras duras, hilandería y tejeduría con desperdicios de algodón; taller de confección de indumentarias; taller para la fabricación de calzado de cuero y fábrica de calzado plástico.

${ }^{12}$ Entrevistas a Neli realizadas por mí, 22 de marzo de 2012 y 26 de febrero de 2013, en la ciudad de Avellaneda.

${ }^{13}$ La fábrica de tejidos Masllorens Hermanos, también conocida como "La Gloria", se instaló en el barrio Crucecita, dentro de la ciudad de Avellaneda, en 1905. Fue producto de la iniciativa de empresarios barceloneses que buscaban extender una filial de la Casa Masllorens en Buenos Aires. Allí se confeccionaba ropa interior, camisetas y mallas de un fino tejido de algodón. Cerró sus puertas a mediados de los años '70. Ver E.Cascante, La Crucesita de Barracas al Sud. Historia e historias. Ed. Dunken, 2003 y artículo sobre Ex Fábrica de Tejidos "La Gloria" de la Secretaría de Cultura, Educación y Promoción de las Artes de Avellaneda: http://www.culteducaavellaneda.com.ar/noticias/wmprint.php?ArtID=147

${ }_{14}$ Ver J.Schvarzer, Las empresas industriales más grandes de la Argentina. Una evaluación. En Revista Desarrollo Económico Vol. 17, No. 66 (Jul. - Sep., 1977), pp. 319-337 


\section{Gabriela Mitidieri}

gran cantidad de mano de obra femenina. Sin embargo, sus compañeras de fábrica, quienes también comenzaban a explorar opciones de trabajo próximas a la zona sur del conurbano bonaerense donde residían, le informaron que para entrar en aquella fábrica del barrio de Barracas era necesario contar con algún tipo de recomendación por parte de un trabajador de la empresa. Su madre le recordó que una vecina tenía un puesto como empleada administrativa en Alpargatas, así que Neli decidió acudir a ella y contarle la situación. La vecina resolvió ayudarla frente al panorama complejo que se avecinaba y muy pronto la joven tuvo la entrevista que le aseguraría la entrada en la sección indumentaria de la fábrica 2 de Alpargatas, cosiendo camisas de hombre, por los siguientes 10 años de su vida.

Neli sabía coser a máquina con destreza y le fue asignada una tarea en la sección de confección de indumentaria, en Fábrica 3:

(...) la que ponía cinturas, ponía cinturas. La que ponía bolsillos, ponía bolsillos. La que ponía el botón este, ponía 'pin!' el botón este. 'pín', botón, tiraba. 'pín', botón, tiraba. Pero en vez de hacer, ponele, 400, tenía que hacer 1500. Estaba marcado con relojitos.

El fragmento ilumina el modo en el que podía ser vivido el trabajo textil dentro de una fábrica y lo que el mismo implicaba: la división del proceso integral en sus mínimos componentes, cronometrar la tarea fragmentada y establecer métodos de control por los cuales la trabajadora en cuestión realizara el máximo posible de producción por hora de trabajo. Al caracterizar Neli el trabajo de la operaria que colocaba botones, ese "pin!" nos devuelve a la línea de producción, a un ritmo aprendido, la repetición del sonido que coincidía con el movimiento replicado una y otra vez.

Los "relojitos" a los que refería Neli eran sólo uno de los aspectos del control minucioso al que estaban expuestas las trabajadoras de Alpargatas que transitaron la fábrica en la década de 1970. El color y tipo de uniforme homogeneizaba el sector y marcaba diferencias tangibles respecto del personal jerárquico de las secciones productivas y respecto de los empleados que desempeñaban tareas administrativas en la empresa. Marta15, operaria del sector indumentaria, afirmaba que, en ese entonces, bastaba ver "uno de clarito", para saber que se estaba acercando un jefe de sector o superior jerárquico. Y eso, tal como fue declarado por una trabajadora, era motivo de miedo, sobre todo para las recién ingresadas ${ }^{16}$.

\footnotetext{
${ }^{15}$ Entrevista a Marta realizada por mí, 2 de marzo de 2012, en la Ciudad Autónoma de Buenos Aires.

16 Una fuente que grafica la información provista por Marta en su testimonio respecto de la jerarquización cromática reflejada en la vestimenta obligatoria son las ilustraciones de uniformes de operarios y personal superior de fábrica insertas en la publicación empresaria "Panorama de Alpargatas" (año 1942, p24 y 25). Imagen online en http://fotovieja.tumblr.com/page/2 Esta revista fue editada anualmente por la empresa entre 1939 y 1943. En la actualidad, las mismas han sido digitalizadas por el área de Recursos Humanos de Alpargatas y están disponibles para su consulta.
} 


\section{La huelga de Alpargatas en 1979}

La supervisión controlaba que cada obrera trabajara al máximo de sus posibilidades, para lo cual se empleaba el sistema de toma tiempos. Consistía en un examen atento de la operaria en cada uno de sus movimientos a lo largo del desarrollo de su tarea. Se tomaban anotaciones respecto del tiempo que le insumía llevar a cabo cada paso de la labor y se definía la cantidad máxima que la obrera en cuestión podía hacer en un lapso de tiempo determinado, estableciéndose así mismo un mínimo requerido para que la obrera alcanzara la producción prefijada. Esto tenía como finalidad la maximización de la productividad de cada sector ${ }^{17}$.

Alcanzar la producción -como denominaban a ese mínimo- era la condición para cobrar un plus salarial que complementaba los sueldos de las operarias. En la línea en la que comenzó Neli -confección de camisas en el sector "Montonera"18, la productividad estaba medida en lotes, cada uno compuesto por 50 camisas. Pero en la percepción de Neli y de sus compañeras, una camisa no era sólo una camisa: eran ocho tareas fragmentadas, cada una de las cuales era absorbida por un conjunto de 10 operarias que al terminar su lote entregaban lo realizado a otras 10 compañeras para la continuación del proceso. Así, un lote de 50 camisas equivalía a 50 fragmentos delanteros de la derecha, 50 de la izquierda, 50 espaldas, 50 mangas derechas, 50 mangas izquierdas, 50 puños izquierdos y 50 derechos. La producción mínima de Neli era de cinco lotes (doscientas cincuenta camisas / quinientos puños). Y no alcanzarla significaba perder ese plus salarial, y además un llamado de atención y amonestaciones públicas por parte de la supervisión. El personal encargado de controlar el ausentismo también tenía la tarea de llevar registro de todas las operarias que no lograban el mínimo impuesto.

A grandes rasgos, este era el cotidiano laboral de los trabajadores de Alpargatas durante la década de 1970. Hacia fines de esa década, la rutina se vería alterada por un proceso huelguístico, organizado tras el no cumplimiento de las

\footnotetext{
${ }^{17}$ Entrevistas realizadas por mí a Marta y Graciela, 2 de marzo de 2012 y a Neli, 22 de marzo de 2012, Ciudad Autónoma de Buenos Aires. Alpargatas a lo largo de su historia se consolidó como uno de los bastiones de la industria textil argentina, no sólo por el volumen de su producción y por la cantidad de personal empleado, sino también por el modo en el que su organización industrial fue a su vez reflejo de las prescripciones de la Federación Industrial Textil Argentina (FITA) y modelo a seguir por el resto de las empresas textiles locales. La relación entre prescripciones y puestas en práctica al interior de Alpargatas no fue de ningún modo azarosa: en el período estudiado el Ingeniero Lorenzo A. Olivero se desempeñó simultáneamente ocupando cargos jerárquicos dentro de la federación patronal y como directivo de la fábrica de Barracas, tal como fuera mencionado en la propia publicación (Ver Revista FITA - Octubre-Diciembre 1968. p29: "Entrevista de empresarios textiles con el Presidente de la Nación."). Con respecto a las iniciativas asociadas a la racionalización de la producción, en la publicación correspondiente al trimestre julio-septiembre de 1968, se incluyó un artículo que llevaba por nombre "Control, gestión y políticas de calidad en la industria textil." (p57-67). El mismo reseñaba los métodos en boga para garantizar la maximización de la calidad: "...podemos anotar la creación de standards propios, estudio de métodos de trabajo, estudio de posibilidades en proyectos de nuevos artículos, establecimiento de especificaciones y tolerancias adecuadas, fijación de los controles a establecer durante el proceso y al final del mismo y formación del personal en los métodos de trabajos más adecuados."

${ }^{18}$ Al año siguiente del ingreso de Neli, en 1972, el nombre de la sección fue cambiado de "Montonera" a "Pampero". El cambio pudo haber estado ligado al despliegue de las primeras acciones públicas que la organización político guerrillera Montoneros realizó en distintos puntos del país, a lo largo de 1970 y 1971.
} 


\title{
Gabriela Mitidieri
}

demandas por aumento salarial. A partir de lo estudiado, es posible que exista un correlato entre dichas demandas y la percepción de que el sistema de bonos por producción no era considerado justo por los trabajadores. Se expresaba así la noción de que un incremento del ingreso correspondía por derecho y que los obreros no debían ser obligados a trabajar al límite de sus fuerzas para percibir una remuneración digna.

\section{La huelga}

En la mañana del viernes 30 de marzo de 1979, la fábrica Alpargatas Barracas amanecía de paro ${ }^{19}$. Sus trabajadores habían resuelto iniciar una huelga por tiempo indeterminado. Reclamaban un aumento del $20 \%$ que se hiciera efectivo apenas comenzado el mes, rechazando el ofrecimiento de una suba del 18\% propuesto tentativamente para el día 16 de abril por la dirección de la empresa.

El lunes 2 de abril, los operarios de Alpargatas recibieron una intimación desde el Ministerio de Trabajo, en la cual se les recordaba la plena vigencia de la ley 21.400 que estipulaba la ilegalidad de toda medida huelguística. Reunidos en una nueva asamblea, se decidió desoir la intimación y proseguir con el reclamo. Ese mismo lunes el personal de seguridad de la planta llevó a cabo el desalojo de los trabajadores que permanecían en su interior sin desarrollar ningún tipo de tareas y dos escribanos públicos labraron las actas correspondientes. Entre esos operarios se encontraba Neli. Según relata más de treinta años después, ella no estaba de acuerdo con la huelga. De todos modos, cuando al día siguiente, martes 3, la empresa anunció un lock-out, es decir, la suspensión total de las actividades de la planta de Barracas, ella se vio afectada por dicha medida al igual que sus casi 4000 compañeros.

Un comunicado fue pegado en afiches en la puerta del establecimiento. En este podía leerse:

\begin{abstract}
Alpargatas, pese al conflicto mantiene su confianza en los integrantes de la empresa y considera que la pausa establecida propiciará la reflexión para lograr el necesario clima de entendimiento mutuo. No obstante, reitera que el único camino válido para solucionar los problemas del trabajo, es el principio del diálogo siempre vigente en forma tradicional en la empresa ${ }^{20}$.
\end{abstract}

El análisis del mensaje difundido por la patronal nos invita a reflexionar acerca de cómo se apeló a la utilización de lenguajes tradicionales en un contexto

\footnotetext{
${ }^{19}$ Información relevada en Diarios Clarín, Crónica, La Opinión y El Día. Del 30 de marzo al 11 de abril de 1979. También fueron consultadas las elaboraciones sobre prensa gremial realizadas por el periodista Senén González, que se encuentran en el archivo homónimo de la Universidad Di Tella. También testimonio de Neli, entrevista realizada por mí el 22 de marzo de 2012.

${ }^{20}$ Citado en "Cierran una planta de Alpargatas por el paro", Diario Clarín, 4 de abril de 1979.
} 


\section{La huelga de Alpargatas en 1979}

distinto y con sentidos diferentes a los asignados originalmente. Así, el mensaje de la patronal construye una imagen de dirección empresaria que vela por el bienestar de sus trabajadores, que como hijos rebeldes deben darse un tiempo para reflexionar sobre su mal comportamiento. Pero este vocabulario que quizás tuviera un asidero en la época de bonanza de la industria textil, no hacía más que contrastar con la experiencia de clase de trabajadores que se disponían a reclamar por un aumento salarial que consideraban justo. Sin embargo, el lock-out era presentado como un paréntesis necesario que llamaba a la reflexión de aquellos que se negaban a encauzar sus reclamos por las vías tradicionales.

Las características de estas vías, es decir, la estructura gremial que pudo seguir funcionando durante la dictadura, serán abordadas en el próximo apartado. Puede inferirse, en una primera instancia, que la emergencia de esta medida huelguística implicó para aquellos trabajadores que se movilizaron, la creencia de que esos canales ya no eran efectivos para la concreción del reclamo. Y la convicción de que ese aumento era justo y necesario, motivó la permanencia de los trabajadores en esa posición intransigente.

Transcurrió una semana hasta el levantamiento del lock-out, pero las actividades no se reanudaron automáticamente sino que se llevó a cabo un operativo cuidadoso de reincorporación de los operarios. Muchos trabajadores no regresarían a su puesto. Y tal como refería Neli en su testimonio, aquellos delegados y delegadas que dinamizaron la medida huelguística, serían castigados con el despido. En su caso, esa misma semana recibió en su domicilio una nota en la que se dejaba constancia de su reincorporación:

Reiniciaremos las tareas progresivamente de acuerdo con las prioridades y necesidades de programación de la producción. En su caso, Ud. deberá concurrir a trabajar el día 9 de abril de 1979, en su turno habitual, con la presente nota y documentos de identidad. En los días sucesivos deberá continuar presentándose con esta nota. ${ }^{21}$

Al volver al testimonio de Neli citado al comienzo del artículo, este ilumina sobre ciertas dimensiones de su experiencia de clase durante la dictadura. En su evocación de la huelga surgió un conflicto similar, pero que había tenido lugar 20 años antes. Para ella, en el reclamo reclamo gremial de 1979 se filtraba una huelga vivida en el seno del hogar familiar. Singularmente, lo hacía a través de lo vivenciado y tal vez transmitido por su madre, otra trabajadora textil de la fábrica Masllorens. La huelga a la que ella había referido fue un conflicto caracterizado por la adhesión masiva dentro de la rama textil. Esta medida implicaba un fuerte rechazo a las medidas de racionalización de la productividad, en el marco del retroceso de las conquistas obreras que signaron el primer peronismo ${ }^{22}$. El

${ }_{21}^{21}$ Circular de la empresa, transcripta en Diario La Opinión del 11 de abril de 1979.

${ }^{22}$ Para un estudio de caso que analiza el gremio textil e indaga en la organización y desenlace de la huelga de 1959 en Bahía Blanca, ver D. Minieri, El sindicalismo peronista en Bahía Blanca. El caso del sindicato de trabajadores textiles (1944 - 1976). Universidad Nacional del 


\section{Gabriela Mitidieri}

desenlace del conflicto era recordado por Neli en estos términos: entraron con la cabeza baja a trabajar, y el sueldo que le dieran. Y esto implicó un fuerte impacto dentro del hogar de Neli y constituyó también un aprendizaje respecto de aquello a lo que se estaba dispuesto para sostener un paro en el ámbito familiar. La dimensión de lo extra-fabril también resonaba dentro del espacio de trabajo en la mención de Neli sobre la interacción entre hombres y mujeres cuyo vínculo de pareja imaginamos clave para la organización de la huelga del 1979.

Al examinar sus palabras observamos la experiencia de una clase obrera heterogénea, con diversas prácticas de resistencia frente a un contexto opresivo. La huelga fue sólo una de las estrategias posibles, la que hizo visibles las demandas postergadas y la que condensó un proceso en el cual fue construida la noción de que aquello que la huelga reclamaba era justo. Por otro lado, la posición de Neli con respecto a la huelga es ilustrativa de lo que se percibía como una correlación de fuerzas desfavorable. Y su no participación fue, de algún modo, recompensada: a diferencia de un considerable número de compañeras y compañeros. Ella mantuvo su puesto en una fábrica que aprovechaba la ocasión del lock out para desprenderse de aquellos trabajadores que habían tenido un rol protagónico en la huelga. Así, puede interpretarse que el cierre de la fábrica durante el conflicto gremial habría sido una medida que tuvo por objetivo desmovilizar a los/as trabajadores/as que organizaron la huelga, fragmentar las posibles alianzas, despojar el espacio de trabajo de toda actividad política.

Nuevos interrogantes aparecen: ¿Quiénes eran esos trabajadores que incitaron a la huelga? ¿Qué características tenía una delegada de sector en este momento? ¿Es posible aprehender los significados que asignaban a sus prácticas en el marco de la huelga?

\section{La organización gremial dentro de la fábrica: la política engenerizada}

Para poner en contexto las diferentes dimensiones del conflicto de Alpargatas, resulta útil realizar una breve caracterización del esquema de organización gremial en la fábrica, vigente al momento de realizarse la huelga.

De acuerdo al estudio de Victoria Basualdo ${ }^{23}$, dicha estructura se consolidó durante la década de 1950 y permaneció esencialmente inalterada en su formato a lo largo del período comprendido en su investigación.

La representación obrera al interior de la fábrica estaba basada, en primera instancia, en la designación de delegados, elegidos por voto simple de los trabajadores de cada sección y departamento de la fábrica. Estas elecciones, que eran convocadas y organizadas por el gremio, involucraban a todos los trabajadores de las tres fábricas de Alpargatas Barracas. Las personas elegidas

Sur. Pp16-18. Disponible online en http://historiapolitica.com/datos/biblioteca/viij minieri.pdf. Para una caracterización del operativo huelguístico en Avellaneda en 1959, ver D.James, Resistencia e Integración. El peronismo y la clase trabajadora argentina. Ed.S.XXI, 2010. P.161.

${ }^{23}$ V.Basualdo, Op.cit $\mathrm{p} 152$ 


\section{La huelga de Alpargatas en 1979}

como delegados generales tenían a su cargo la coordinación de los delegados de un grupo de departamentos. Estos últimos eran a veces llamados sub-delegados ya que estaban por debajo de los delegados generales. Toda la estructura de representación era encabezada por el secretario general de la fábrica, quien además lideraba la comisión interna, junto con otros delegados generales.

Por las dimensiones y cantidad de personal empleado, existió desde la creación de la Asociación Obrera Textil, una filial del gremio (también llamada delegación Barracas o Patricios) exclusivamente dedicada a representar a los trabajadores de Alpargatas. Y el secretario general gremial de la empresa era simultáneamente el secretario general de la filial textil.

Basualdo rastrea una tendencia creciente a que las mujeres operarias ocuparan el puesto de delegadas de sección en Alpargatas, aunque esto no se tradujo en una presencia análoga en puestos jerárquicos dentro de la comisión interna.

Nora ${ }^{24}$ fue delegada gremial en repetidas oportunidades, a lo largo de su trayectoria como trabajadora textil y activista política en Palabra Obrera primero y luego en el Partido Socialista de los Trabajadores ${ }^{25}$. Su testimonio es representativo de lo expuesto por Marcela Nari en su investigación respecto a los obstáculos que encontraron muchas mujeres para conciliar la vida familiar con el activismo gremial ${ }^{26}$

Era un bicho raro yo. Era una delegada mujer, que era difícil que una delegada mujer fuera delegada por más de un tiempo cortito porque los novios y los maridos no las dejaban ${ }^{27}$.

Para enmarcar las palabras de Nora, es preciso indagar acerca de cómo el género delimitaba tareas específicas al interior de la fábrica en el período analizado. El personal jerárquico estaba en su mayoría compuesto por varones, y el máximo ascenso al que una mujer podía aspirar era como empleada dentro del área administrativo-contable.

En cuanto a las relaciones entre operarios varones y mujeres que compartían un mismo rango de subordinación respecto del personal jerárquico, el contacto entre ellos se encontraba limitado a algunos sectores específicos o a situaciones concretas dentro de la jornada laboral que requirieran la interacción. Los hombres solían ocupar puestos en la sección Tejeduría, también podían estar

\footnotetext{
${ }^{24}$ Entrevista a Nora realizada por mí, 24 febrero 2013, Ciudad Autónoma de Buenos Aires.

${ }^{25}$ Se conoció con el nombre de Palabra Obrera a la agrupación política (y a su publicación homónima) creada por el histórico militante trotskista Nahuel Moreno a mediados de la década de 1950. De la confluencia entre esta organización y el Frente Revolucionario Indoamericano Popular, dirigido por Mario Roberto Santucho, nacería el 25 de mayo de 1965 el Partido Revolucionario de los Trabajadores.

${ }^{26}$ M. Nari, Politicas de maternidad y maternalismo politico. Buenos Aires, 1890-1940. Ed.Biblos, 2004.

${ }^{27}$ Entrevista a Nora realizada por mí, 24 febrero de 2013, en la Ciudad Autónoma de Buenos Aires.
} 


\section{Gabriela Mitidieri}

empleados como mecánicos, eran operarios de producción en el turno noche vedado por ley para las mujeres- o encargarse de transportar materia prima o lotes manufacturados a través de la planta. En las significaciones presentes en los testimonios orales de las ex obreras, se registra una percepción común a todas ellas de que las "máquinas pesadas" eran operadas por varones. Y si bien la destreza requerida no necesariamente era mayor que la que implicaba el trabajo con las máquinas de los sectores "femeninos", había también supuestos generizados implícitos que moldeaban la percepción que los varones tenían sobre su propia labor y sobre la de sus compañeras ${ }^{28}$. De acuerdo a Roque ${ }^{29}$, trabajador textil desde mediados de la década del ' 40 hasta la década del '60, y actualmente empleado de la Asociación Obrera Textil, el trabajo del tejedor era la labor fundamental de todo el proceso, la que permitía que todas las otras se realizaran. Roque recuerda cómo en su fábrica los tejedores cumplían el rol masculino de proveer a los sectores femeninos del material a partir del cual todo el resto de las actividades productivas se realizarían. No obstante, el de tejedor no era un rol exclusivo de los varones, pero sí entrañaba un prestigio masculinizado. Así mismo, al caracterizar el trabajo de costureras e hilanderas, este trabajador enfatiza la "delicadeza" de la actividad desarrollada y así explica que la contratación mayoritaria de mujeres en la rama textil estuviera ligada a la habilidad femenina para estas labores.

De esa manera, calificaciones consideradas masculinas, como la fuerza física o el manejo de maquinaria, eran mejor remuneradas que las calificaciones atribuidas al sexo femenino: destreza y habilidad manual. Por otra parte, mientras que la de tejedor podía ser entendida como una labor asociada a atributos ligados a la masculinidad, en los testimonios de las trabajadoras de Alpargatas entrevistadas, las delegadas de sector y de fábrica que lograron consolidar una posición gremial sostenida fueron frecuentemente recordadas como "machonas", "mujeres grandotas, muy masculinas"30. Esto invita a pensar que, para estas trabajadoras, el despliegue político en el ámbito de lo público podía continuar asociado a un desempeño masculino. Y esto podía convivir, en tensión, con diversas manifestaciones femeninas que han sido interpretadas por la investigadora Isabella Cosse como rupturas con respecto al ideal tradicional de domesticidad en las décadas de 1960-197031.

\footnotetext{
${ }^{28}$ Entrevista a Nora realizada por mí, 24 febrero de 2013, en la Ciudad Autónoma de Buenos Aires. Entrevista a Neli realizada por mí, 22 de marzo de 2012 y 26 de febrero de 2013, en la ciudad de Avellaneda. Entrevista a Marta y Graciela realizada por mí, 2 de marzo de 2012, en la Ciudad Autónoma de Buenos Aires.

${ }_{29}$ Entrevista a Roque realizada por mí, 10 de enero de 2013, en la sede de la Asociación Obrera Textil, Ciudad Autónoma de Buenos Aires.

${ }^{30}$ Entrevista colectiva realizada por mí a ex operarias de Alpargatas Barracas, 2 de marzo de 2012, Ciudad Autónoma de Buenos Aires. Entrevistas a Neli realizadas por mí, 22 de marzo de 2012 y 26 de febrero de 2013, ciudad de Avellaneda.

${ }^{31}$ I. Cosse, Pareja, sexualidad y familia en los años sesenta. Una revolución discreta en Buenos Aires. Ed.Siglo XXI, 2010
} 


\section{La huelga de Alpargatas en 1979}

Si bien existían múltiples diferencias, el proceso de convertirse en delegada tenía puntos en común con los itinerarios de sus pares varones. Había que dominar la propia tarea, conocer la máquina, adquirir el oficio. Nora provenía de una familia ferroviaria y había abandonado su Bahía Blanca natal para profundizar una militancia político-sindical. La motivaba la posibilidad de que ese activismo pudiera ser llevado adelante como trabajadora fabril en Buenos Aires. Cuando en el año 1964 comenzó a trabajar en Alpargatas, su objetivo estaba puesto en transformarse en delegada. Para ella, se trataba de obtener el respeto de las compañeras, dominando una de las tareas más prestigiosas dentro del proceso productivo textil:

Yo tenía tanto afán de llegar a ser tejedora, porque la asociación que vos seas una luchadora pero que tengas el oficio más bajito no va, porque no te respetan tus compañeros. Entonces yo me tuve que conquistar a todas las tanas viejas y gallegas, entonces yo me apuraba en poner el hilado, entonces siempre tenían bien alimentado los telares y me apuraba y me hacía el espacio y me ponía a disposición para que ellas me enseñen. Entonces ellas veían que yo era tenaz. Y yo a los 10 meses era tejedora. Tejedora, tejedora eh! Y atendía 16 telares, bah, todas atendíamos 16 telares. Así que al poco tiempo me eligieron delegada. No porque fuera tejedora nomás, porque era buena compañera, solidaria, porque me querían.

Para Sofía ${ }^{32}$, delegada de Alpargatas Varela, el delegado debía cumplir funciones muy concretas de asistencia al compañero/a:

Y el delegado de sector se acerca, cuando entra gente nueva, y te dice, bueno, yo soy el delegado o la delegada de sector, para avisarnos cuáles son nuestras cosas que nos corresponden, para contarnos... hacernos saber qué nos corresponde en salud, y a donde nos corresponde para hacernos el inicio del carnet, ¿no es cierto? Tanto para la parte recreativa, como para la parte de salud, todas esas cosas. Y bueno, y después cuando se presenta a elecciones, su oportunidad, me dicen a mí que si yo quería ser delegada, y bueno, como me gustaba. (...) ya tenía yo un par de años, ya tenía como cuatro años, cuatro, cinco años, porque uno tiene que saber más o menos del tema. Saber, por lo menos tener los conocimientos que hay que tener, qué es lo principal del trabajo. Yo no puedo ir a defender un compañero, si no se cómo se coloca hasta... por decirte algo... Tengo que saber de la máquina en la que se trabaja, de cómo funciona, qué demoras te puede traer, qué son las cosas que se nos rompen, porque todas esas cosas te traen una demora. A mí, una máquina me está rompiendo mucho las agujas, yo tengo que llamar al mecánico y cada vez que llamo al mecánico para que coloque la aguja, son minutos, y con la producción, los minutos se suman y se hacen muchos.

${ }^{32}$ Entrevista a Sofía realizada por mí, 28 de febrero de 2013, en la sede de la Asociación Obrera Textil, Ciudad Autónoma de Buenos Aires. 


\section{Gabriela Mitidieri}

$\mathrm{Al}$ analizar sus palabras vemos, por un lado, que en el período estudiado la Asociación Obrera Textil había capitalizado una serie de conquistas para el gremio que implicaban ventajas materiales concretas para sus trabajadores. El rol primero del delegado, para Sofía, era hacer conocer esas conquistas a los ingresantes e indicarles los procedimientos para que pudieran gozar de ellas. Por otro lado, de acuerdo a esta antigua delegada, era de vital importancia que quien tuviera este rol gremial contara con un profundo conocimiento del proceso de trabajo del propio sector. Y, en el período estudiado, un verdadero conocimiento del proceso productivo no era tal si no contemplaba la necesidad de que todos los compañeros pudieran cumplir con la productividad mínima exigida por la gerencia. En ese sentido, conocer la máquina y sus falencias regulares resultaba una información estratégica a la hora de defender a los trabajadores del sector. Una noción de lo que se consideraba justo se asoma en el testimonio de Sofía: como trabajadora se aceptaba cumplir con la productividad exigida pero debían contarse con las condiciones técnicas adecuadas para hacerlo. De lo contrario la cantidad que se produjera estaría sujeta a las demoras periódicas que las averías de la máquina ocasionaban.

Para situar históricamente el proceso que organizaba la jornada de estas trabajadoras -tal como fuera reseñado en el primer apartado- es preciso señalar que, tras el desenlace negativo de las huelgas textiles del período 1959-196133 aquellas que transitara Neli junto a su madre- que se oponían a la racionalización de la producción, y ya establecido en el Convenio Colectivo del año '61 el poder de la patronal para fijar el ritmo de trabajo en las fábricas, Alpargatas instaló técnicos de racionalización y toma-tiempos que se sumaron a la planta como personal efectivo. De sus registros favorables o desfavorables dependían los bonos obtenidos por los operarios, las llamadas de atención, las suspensiones y despidos. De esa manera, a lo largo de la década del '60 y acentuándose a comienzos del '70, los empresarios industriales textiles desarrollaron una serie de estrategias que apuntaban a amortiguar la pérdida progresiva de ganancias, asociadas a la baja en el comercio de exportación ${ }^{34}$. Se observa así una tendencia hacia la concentración en un reducido número de grandes unidades fabriles y la intensificación de la explotación de la mano de obra. Esta fue la realidad de Alpargatas en este período,

\footnotetext{
${ }^{33}$ Las huelgas de la rama textil se insertaron en el marco más amplio de una ofensiva obrera al gobierno de Frondizi. Ver por ejemplo D. James, op.cit, Pp158-174. En una línea diferente, A.Schneider, Dinámica del movimiento sindical, 1955-1973, en Revista Archivos de historia del movimiento obrero y la izquierda. Año I - № 2 (Marzo 2013).

${ }_{34}$ Para una caracterización general de la economía del período, ver E.Basualdo, Estudios de Historia Económica Argentina, Ed. Siglo XXI, 2006. Apartado 2.2, pág 42-95. Para un análisis específico de la industria textil frente a esta coyuntura económica, ver A. Canitrot, J.Fidel, M. Juillerat y J. Lucangeli, El empleo en la industria textil argentina. Análisis de comportamiento y de elección tecnológica. Revista Desarrollo Económico, Vol 16, № 63 (Oct-Dic, 1976) Ver también el análisis contemporáneo que realizan los militantes del Partido Comunista de La Boca sobre las características de la racionalización de la producción en la fábrica en el libro, Alpargatas S.A. Argentina o de los monopolios, Ed.Anteo, 1974.
} 


\title{
La huelga de Alpargatas en 1979
}

constituyéndose junto con empresas como Sudamtex y Grafa, en las fábricas que marcaban el ritmo de la industria textil del país.

Fue en ese marco que Hortensia se convirtió en delegada. De acuerdo a su testimonio, la vocación jugó un papel importante en ese proceso:

\begin{abstract}
Me hice delegada por vocación. Primero, por elección de mis compañeros. Por vocación y por conocimiento de mi trabajo, porque vos te vas haciendo... porque para ser un delegado, para ser un buen delegado... cualquier delegado puede hacer, y si no tiene vocación o no tiene voluntad tiene que dejarle lugar a otra persona. Porque no hay ningún empresario, ningún patrón que te puede poner freno. (...) En aquel entonces a los delegados estábamos por elección de nuestros compañeros y porque realmente sentíamos vocación por lo que hacíamos, muchas ganas de aprender y buenos sentimientos, porque para ser un buen delegado tenés que ser una buena persona y situarte en el centro y hacer el equilibro para ambos lados. Yo nunca fui de amparar a un trabajador vago o a un trabajador que no quisiera hacerlo bien porque realmente eso es quitar fuente de trabajo al resto. Pero la empresa le tenía que dar las condiciones y tenían que ser justos, empezando por el supervisor, el jefe del sector, tenían que ser justos con el compañero. Después el conocimiento mecánico lo vas aprendiendo, porque vas aprendiendo desde tu máquina si anda mal, qué motivo tiene, si se cayó un taco, vos vas aprendiendo. Por eso cuando vas a hacer un reclamo, ya sabés, tengo este problema en la máquina. Yo me acuerdo que entraba en el sector y escuchaba el taco y sabía que aquel telar andaba mal. Y así aprendíamos todos ${ }^{35}$.
\end{abstract}

En las palabras de Hortensia también hay una noción de ecuanimidad que para ella es central en el desempeño de un delegado. Es posible que esto guarde estrecha relación con la corriente gremial en la que se encuadró Hortensia a lo largo de su trayectoria como delegada: la lista marrón, encabezada por el dirigente textil Pedro Goyeneche. En ese sentido, adherían a una tradición peronista de conciliación de clases, en la que cada una de las partes debía cumplir con su rol para propender a la armonía general de la empresa. Sus nociones de justicia abrevan en esa línea: una delegada debe velar por los derechos de sus compañeros pero estos a su vez tienen un compromiso para con el trabajo realizado. Al igual que Sofía y que Nora, Hortensia también consideraba indispensable el conocimiento del proceso de trabajo y de las especificidades de la maquinaria utilizada como precondición para ser una delegada legítima frente a los trabajadores y frente a la patronal. No obstante, su aseveración "ningún patrón puede ponerte freno", permite entrever la complejidad de la figura del delegado o delegada dentro de la fábrica, en el período analizado.

Así, una paradoja atravesaría la historia gremial de Alpargatas en este período: si bien la línea oficial de la comisión interna se caracterizaba por esta

${ }^{35}$ Entrevista a Hortensia realizada por mí, 28 de febrero de 2013, en la sede de la Asociación Obrera Textil, Ciudad Autónoma de Buenos Aires. 


\section{Gabriela Mitidieri}

posición de ecuanimidad, -el delegado o la delegada como un mediador entre los intereses de la patronal y de sus compañeros, en lugar de un representante que defendía las demandas de sus pares-, entre mediados de la década del '60 y el conflicto huelguístico de 1979, las posturas disidentes no cesaron. La estructura gremial por un lado canalizaba esas demandas y aseguraba a la patronal un cauce ordenado de mediación, tal como se expresaba en el comunicado que daba aviso del lock-out durante la huelga. La existencia de dicha estructura también era un resguardo para los trabajadores frente a políticas entendidas como arbitrarias o abusivas. Por lo menos, de ese modo fue comprendido por estas trabajadoras. No obstante, será en momentos de enfrentamiento abierto con la patronal que las tensiones que no lograban ser encauzadas de manera eficaz, podrán observarse con más claridad.

Al volver a la huelga de 1979, Hortensia refiere que en el momento en el que tuvo lugar el conflicto, ella se desempeñaba como delegada de la Fábrica 3, donde comenzó el reclamo. No estaba de acuerdo con la medida, porque consideraba que violentaba los canales tradicionales de diálogo. Además, en un comienzo, tuvo lugar al interior de la fábrica de la que ella era delegada, poniendo en cuestión, de cierto modo, su función de intermediaria entre sus compañeros y los directivos. Pero, por el rol que ella cumplía debía estar al tanto de lo que sucediera para poder mediar, si la circunstancia lo ameritaba. Y en efecto, tal como se mencionó, el hecho de que la huelga tuviera lugar era un indicio de que la hegemonía de la línea oficial del sindicato intervenido era, a su vez, relativa, condicional. Su legitimidad dependía de que fueran reconocidas las demandas efectuadas desde las bases, aún en un contexto de represión abierta contra los trabajadores.

¿Y quiénes eran esos trabajadores, esas bases, durante la dictadura? Si bien es difícil precisar la adscripción política de cada uno de ellos, se puede inferir que existían varios en una situación similar a la de Alberto. Alberto ${ }^{36}$ era mecánico de telares en la fábrica y durante su paso por Alpargatas un compañero logró sumarlo a la organización trotskista Palabra Obrera. En su testimonio se registran elementos que dan cuenta de que, más allá de la diversidad política entre los trabajadores, pervivían tradiciones de solidaridad de clase, de vital importancia en contextos adversos. Recuerda Alberto que entre compañeros, aún de distintos niveles jerárquicos, se formaban alianzas que tenían como finalidad protegerse frente a circunstanciales despidos. En su testimonio él refiere concretamente al vínculo que tejió con su jefe de sector quien lo alertó acerca de un nuevo compañero de trabajo: un hombre mandado por la gerencia "de encubierto" CITA para detectar militantes y así despedirlos. En ese sentido, esa tradición de solidaridad, esa cultura de clase, alimentaba una noción compartida de que un despido por razones políticas era injusto. Y es posible que dicha noción se fortaleciera al interior de la fábrica en un contexto político de extrema arbitrariedad.

${ }^{36}$ Entrevista a Alberto realizada por mí, 25 de mayo de 2013, Ciudad Autónoma de Buenos Aires. 


\section{La huelga de Alpargatas en 1979}

Alberto describe hoy con emoción sus días en la fábrica, la huelga y sus compañeros. A diferencia de Neli, él no pudo mantener su puesto de trabajo en la fábrica después del lock-out. No obstante, pronto consiguió un empleo como mecánico en la empresa Noel, a pocas cuadras de distancia de Alpargatas. Allí, una estrategia de organización que puso en marcha junto con sus compañeras (Noel también empleaba un conjunto significativo de mujeres en sus secciones) fue la de convocar a partidos de futbol femeninos inter-fabriles como medio para mantenerse en contacto sin despertar sospechas ${ }^{37}$.

De esta manera, pueden ser rastreadas distintas estrategias que estos trabajadores y delegadas textiles consiguieron desarrollar en el período estudiado, en un ámbito laboral en el que el género operó como organizador de jerarquías y también moldeó las formas que dichas estrategias adoptaron. Estas prácticas estuvieron dirigidas a la consecución de mejoras laborales, a partir de nociones de lo que se consideraba que correspondía por derecho, y se apoyaron en una estructura gremial preexistente que encauzaba las demandas de los trabajadores y mediaba entre estos y la patronal. Así, convertirse en delegada implicaba detentar un conocimiento profundo sobre las condiciones de trabajo (tiempos, maquinaria, productividad, sanciones) y los derechos conquistados que no podían vulnerarse (obra social, pago de horas extras, derecho a organizarse gremialmente, etc.). Pero, por otro lado, aquellos que no lograban insertar sus demandas dentro de los cauces convenidos, también desplegaban estrategias de negociación y resistencia: la solidaridad entre compañeros para impedir sanciones y despidos, las prácticas extra-fabriles que impugnaban las prohibiciones de organizarse dentro del espacio de trabajo, entre otras.

\section{Palabras finales}

Este artículo intentó reconstruir el marco en el cual fue desarrollada una medida huelguística. El acento puesto en lo justo o lo que correspondía por derecho guió este ejercicio historiográfico, dando por resultado una aproximación parcial a las prácticas de resistencia, impugnación y negociación desplegadas por distintos trabajadores de la fábrica, que pudieron tener lugar en el momento histórico que enmarca la realización de la huelga de Alpargatas de 1979.

En el primer apartado se trató de revisar las características del ámbito fabril en donde tuvo lugar la huelga, entendiendo esta puesta en contexto como un elemento clave para comprender la medida. El tipo de producción realizada, la organización del trabajo, los distintos aspectos del control dentro de la fábrica fueron analizados, así como el ingreso y las vivencias cotidianas de Neli, una operaria de Alpargatas en la década de 1970.

Luego nos adentramos en los pormenores de la huelga: cuándo y cómo comenzó, los motivos de la medida, aquello que se reclamaba y también la ofensiva

\footnotetext{
${ }^{37}$ Alberto falleció el 5 de febrero del 2014. Le estoy enormemente agradecida por la posibilidad que me brindó de conocer su historia y la de sus compañeros.
} 


\section{Gabriela Mitidieri}

de la patronal consistente en un lock-out que desarticuló en buena medida la organización del paro. Para profundizar en un análisis que tuviera en cuenta la perspectiva de una trabajadora acerca del conflicto, se recuperó nuevamente el testimonio de Neli y cómo su decisión acerca de si participar o no de la huelga enlazaba con la experiencia de clase, como hija de una trabajadora textil.

En un tercer momento, se abordó como un aspecto ineludible para enmarcar la realización de la huelga, la organización gremial dentro de la fábrica. Además de revisar, a la luz de la investigación de Basualdo, las características de dicha organización, el énfasis estuvo puesto en indagar acerca de cómo el género vertebró jerarquías al interior de la fábrica, convirtiéndose en una variable necesaria para analizar las prácticas de las delegadas de Alpargatas. Seguidamente, en la línea de continuar con un análisis que aportara nuevos elementos para estudiar la huelga, se trató de enfocar una vez más en los testimonios de distintas delegadas de la fábrica, en particular revisando aquello que estas mujeres consideraron como justo o que correspondía por derecho. Así, se intentó ver bajo una nueva luz las distintas estrategias desplegadas por estos sujetos en un contexto adverso para la organización gremial.

De esta manera, el presente análisis se propuso servir como un aporte para continuar reflexionando acerca de las experiencias sociales de organización y lucha de la clase trabajadora a lo largo de la última dictadura militar. Una clase heterogénea, que recibió múltiples embates y que, en ese sentido, ideó diversas estrategias para continuar expresando sus demandas.

\section{Bibliografía}

AA.VV. Fábrica Argentina de Alpargatas S.A.: ¿Argentina o de los monopolios? Partido Comunista del Barrio de La Boca, Ed.Anteo 1974

A. Abós, Las organizaciones sindicales y el poder militar. Ed.CEAL, 1984.

A. Canitrot, J.Fidel, M. Juillerat y J. Lucangeli, El empleo en la industria textil argentina. Análisis de comportamiento y de elección tecnológica. Revista Desarrollo Económico, Vol 16, № 63 (Oct-Dic, 1976)

A. Schneider, Dinámica del movimiento sindical, 1955-1973, en Revista Archivos de historia del movimiento obrero y la izquierda. Año I - № 2 (Marzo 2013).

Ladran Sancho... Dictadura y clase obrera en la zona norte del Gran Buenos Aires, en H. Camarero, P. Pozzi y A. Schneider, De la Revolución Libertadora al Menemismo. Historia Social y Política Argentina, Ed. Imago Mundi, 2000.

D. Dicósimo, Dirigentes Sindicales, racionalización y conflictos durante la última dictadura militar. Revista Entrepasados, Año XV, № 29, 2006.

D. James, Resistencia e Integración. El peronismo y la clase trabajadora argentina. Ed.S.XXI, 2010. Pp158-174. 


\section{La huelga de Alpargatas en 1979}

D. Minieri, El sindicalismo peronista en Bahía Blanca. El caso del sindicato de trabajadores textiles (1944 - 1976). Universidad Nacional del Sur. Pp16-18. Disponible online en http://historiapolitica.com/datos/biblioteca/viij_minieri.pdf. E. Basualdo, Estudios de Historia Económica Argentina, Ed. Siglo XXI, 2006. Apartado 2.2, pág 42-95.

E. Cascante, La Crucesita de Barracas al Sud. Historia e historias. Ed. Dunken, 2003.

F. Lorenz, Los zapatos de Carlito. Una historia de los trabajadores navales de Tigre en la década del 70, Ed. Norma, 2007.

J. Schvarzer, Las empresas industriales más grandes de la Argentina. Una evaluación. En Revista Desarrollo Económico Vol. 17, No. 66 (Jul. - Sep., 1977), pp. 319-337

M. Ceva, Empresas, trabajo e inmigración en la Argentina. Los casos de la Fábrica Argentina de Alpargatas y la Algodonera Flandria (1887-1955). Ed. Biblos, 2010.

M. Schiavi, Organización y conflictividad textil:La Fábrica Argentina de Alpargatas a comienzos del primer gobierno peronista. Revista Mundos do Trabalho, vol. 4, n. 8, 2012, p. 252-272.

M. Nari, Politicas de maternidad y maternalismo politico. Buenos Aires, 1890-1940. Ed.Biblos, 2004.

El trabajo a domicilio y las obreras (1890-1918), en Razón y Revolución, nro. 10, 2002.

P. Pozzi, La oposición obrera a la dictadura. Ed. Imago Mundi, 2008 (Primera Edición: 1988).

V. Basualdo, Complicidad patronal-militar en la última dictadura argentina: Los casos de Acindar, Astarsa, Dálmine Siderca, Ford, Ledesma y Mercedes Benz, Revista Engranajes (Federación de Trabajadores de la Industria y Afines), N5, 2006.

La participación de trabajadores y sindicalistas en la campaña internacional contra la última dictadura militar argentina, en Revista Sociedad No. 25, Facultad de Ciencias Sociales de la Universidad de Buenos Aires, 2006 Labor and structural change: Shop-floor organization and militancy in Argentine industrial factories (1943-1983), Tesis de Doctorado, Columbia University, 2010. 